\title{
Os quatro problemas das instituições econômicas e o debate do cálculo econômico socialista
}

\author{
The four issues of economic institutions and the socialist economic calculation debate \\ Los cuatro problemas de las instituciones económicas y el debate del cálculo \\ económico socialista
}

José Hamilton dos Santos Batista*

\author{
Palavras-chave: \\ Socialismo, \\ Instituições, \\ Aprendizado, \\ Cálculo Econômico, \\ Racionalismo Pancrítico, \\ Hayek, \\ Mises.
}

\begin{tabular}{l}
\hline Keywords: \\
Socialism, \\
Institutions, \\
Learning, \\
Economic Calculation, \\
Pancritical Rationalism, \\
Hayek, \\
Mises.
\end{tabular}

\section{Palabras clave:}

Socialismo,

Instituciones,

Aprendizaje,

Cálculo Económico,

Racionalismo Pancrítico,

Hayek,

Mises.

\begin{abstract}
Resumo: $\mathrm{O}$ atual trabalho tem por objetivo simultaneamente a elaboração de um framework analítico para se organizar as relações dos problemas das instituições econômicas, em especial sua aplicação para o problema do cálculo econômico socialista e a de propor uma leitura do debate. Pouco se analisou sobre a relação dos problemas, o que levou a uma barreira linguística que impede o entendimento das propostas de Mises e Hayek. A investigação de tais problemas será guiada com base nos princípios do Racionalismo Pancrítico de Bartley-Popper, onde a análise das instituições como regras que permitem maior ou menor capacidade de aprendizado de um sistema, se transfere para os problemas econômicos e permite clarificar os dois problemas mais controversos do debate: $\mathrm{O}$ do conhecimento e o do seu uso. Se o artigo for bem-sucedido em clarificar tais problemas, naturalmente surge um framework de como os problemas se encaixam e onde as diferentes propostas de socialismo falham.
\end{abstract}

Abstract: The present work has as its objective the elaboration of an analytical framework to organize the relations of economic institutions issues, as well as their application to the issue of the socialist economic calculation, proposing a reading on the discussion. Little was analyzed about the relationship of the issues, which led to a language barrier hindering the understanding of Mises and Hayek's proposals. The investigation of such issues will be guided by Bartley-Popper's principles of Pancritical Rationalism, where the institutions' analysis as rules allowing greater or lesser learning capacity of a system, is transferred to the economic issues and allows to clarify the two most controversial issues of the discussion: knowledge and its use. If the article succeeds in clarifying such issues, a framework emerges naturally as to how issues fit together and where different proposals for socialism fail.

Resumen: El presente trabajo tiene como objetivo simultáneamente la elaboración de un framework analítico para organizar las relaciones de los problemas de las instituciones económicas, en especial su aplicación para el problema del cálculo económico socialista y proponer una lectura del debate. Poco se analizó sobre la relación de los problemas, lo que conllevó a una barrera lingüística que impide el entendimiento de las propuestas de Mises y Hayek. La investigación de tales problemas será guiada en base a los principios del Racionalismo Pancrítico de Bartley-Popper, donde el análisis de las instituciones como reglas que permiten una mayor o menor capacidad de aprendizaje de un sistema, se transfiere a los problemas económicos y permite aclarar los dos problemas más controvertidos del debate: El del conocimiento y el del uso. Si el artículo tiene éxito en aclarar tales problemas, naturalmente surge un framework de cómo los problemas parecen encajarse y dónde las diferentes propuestas de socialismo fallan.

\footnotetext{
* Graduado em Ciências Econômicas pela Universidade Federal de Roraima (UFRR). Atualmente Professor Substituto pela Universidade
} Federal de Roraima. E-mail: jhsbrr@gmail.com 


\section{Introdução}

Que significa dizer que uma instituição ou sistema de instituições, econômica(s) "funciona(m)"? Quais são os problemas que tais instituições econômicas devem solucionar para que possam funcionar? E sob quais condições tais instituições funcionam? Essas perguntas emolduram o debate a respeito do cálculo econômico sob o socialismo. Diante disso, o presente trabalho tem por objetivo fornecer um esquema analítico que ajude a responder tais questionamentos, e por consequência, facilitar a análise do debate na clarificação de certos pontos.

Desde o início de sua história, a ciência econômica tem como um de seus principais interesses, a análise comparativa entre distintas instituições econômicas. Pode-se traçar tal preocupação em Adam Smith (2016) e em outros economistas clássicos (SAY, 2008, p. 9). Mas o que seriam instituições? E o que faria de uma instituição, uma instituição econômica?

De acordo com Douglass North (2014, p. 14), instituições são "quaisquer formas de restrição que os seres humanos engendrem para moldar a interação humana". Em uma terminologia hayekiana, instituições são arranjos de normas, ou regras, de conduta humana. Dito isso, existem diversos tipos de instituições, o que leva à seguinte indagação: o que faria uma instituição ser econômica em comparação à instituições como a linguagem, a estética etc., que não são econômicas?

Para os propósitos dessa pesquisa, instituições econômicas são todas aquelas que limitam, de forma coercitiva, o uso de recursos, em geral. A partir disso, é necessário que se diferencie uma limitação coercitiva de uma compelativa.

Limitações coercitivas referem-se à normas de conduta que os indivíduos são coagidos a seguir. Ou seja, a maneira que tais normas alteram seus custos de oportunidade, através da ameaça, do uso da coerção no grau mais elevado, da utilização de força ou violência. Por sua vez, as normas que se aplicam de forma compelativas, compelem os indivíduos a segui-las, alterando o custo de oportunidade de certas escolhas por meio de respostas meramente sociais, das quais algumas possuem um certo grau de coerção, mas que não se vale da violência, ou da força, para sua observação.

Essa distinção permite inferir que o direito à propriedade privada, e toda estrutura de normas de conduta que o ampara, é uma instituição econômica, enquanto as normas da língua portuguesa não constituem uma instituição econômica. Cumpre consignar que tal distinção não é rígida e nem perfeita; todavia, é capaz de fornecer um framework analítico valioso à análise aqui exposta.

Dito isso, o que significa dizer que uma instituição econômica "funciona"? Pois bem. Importante destacar que a Economia é um sistema, e como todo sistema, temos partes interagindo sobre determinadas regras ${ }^{1}$ (BERTALANFLFY, 2006, p. 84). As instituições são parte das regras que ditam como o sistema funciona. Nossa pergunta é se tais instituições fazem com que tais partes interajam de maneira a resolver o problema econômico central, que será explorado a seguir.

\footnotetext{
1 “Um sistema pode ser definido como um complexo de elementos em interação” (BERTALANFFY, 2006, p. 84).
} 
No presente estudo, a questão preliminar consiste em indagar se uma instituição consegue, em princípio, resolver tal problema, e apenas posteriormente, o questionamento será sob quais condições ela conseguiria ou não resolver tal problema. Com efeito, a diferença entre as mencionadas perguntas é essencial para entender a dinâmica do debate sobre a possibilidade do cálculo econômico na economia socialista

Os problemas a seguir não são os únicos problemas relevantes na Economia, nem mesmo os únicos quando se trata do debate sobre a possibilidade do cálculo econômico socialista, mas fornecem uma estrutura que facilita a análise da querela e o esquema analítico fornecido permite futuras expansões. Dito isso, o primeiro problema a ser enfrentado nos levará às origens da economia moderna.

\section{O problema central - o problema econômico}

O primeiro problema é o problema econômico, que consiste em como utilizar os meios, que servem para atingir fins alternativos com distintas importâncias relativas, quando sua quantidade é tal que não permite atingir todos os fins. Esse problema é tão importante que é o problema que define o campo de estudo chamado de Ciência Econômica.

Na famosa elaboração de Lionel Robbins (2012, p. 15) “a Economia é a ciência que estuda o comportamento humano como uma relação entre fins e meios escassos que têm usos alternativos". A ciência econômica investiga os princípios pelos quais é decidido como utilizar os meios, e todos os problemas conectados a tais princípios.

O problema econômico, como enfrentado pelos agentes econômicos, é de qual deve ser o plano alocativo que permitirá ao indivíduo alcançar um conjunto de fins com maior importância relativa.

\section{Como coloca Mises:}

No que se refere a valor de uso subjetivo, ao ponto de vista especificamente humano e aos dilemas do agente homem, a tecnologia não tem nada a ensinar. A tecnologia ignora o problema econômico: empregar os meios disponíveis de tal maneira que uma necessidade mais urgentemente sentida não deixe de ser atendida porque os meios apropriados à sua satisfação foram empregados desperdiçados - para atingir uma necessidade menos urgentemente sentida. (MISES, 2010, p. 259)

Um plano alocativo deve então ser entendido como uma relação, ou arranjo, entre os meios e os fins específicos que irão servir ser utilizados para atingir, fruto da escolha dos indivíduos.

Para que esse problema exista é necessário que se atenda à duas condições. A primeira das condições é que exista algum ente que possua fins com importâncias relativas distintas; a segunda condição é que a quantidade de coisas consideradas como meios, devido a sua capacidade de fazer esse ente atingir seus fins, seja considerada insuficiente para atingir todos os fins.

Caso se façam presentes essas duas condições, surgirá o problema econômico. O problema econômico é condição necessária e suficiente para afirmar que o indivíduo efetua ou efetuará escolhas. Não é à toa que a teoria que descreve os princípios por trás da solução de tal problema seja chamada de lógica da escolha. 
Enquanto existirem agentes que façam escolhas existirá problema econômico. Negar, em certo contexto, que não exista o problema econômico é negar que, em tal contexto, será necessário fazer escolhas, inversamente enquanto existir agentes em situação que os leva a fazer escolhas, existirá o problema econômico².

De acordo com a lógica da escolha, os indivíduos irão fazer escolhas de maneira que irão alocar os recursos que dispõem para atingir a combinação de fins que possuem maior importância, e assim abrirão mão da segundo combinação de fins mais importante.

Uma maneira alternativa de expressar o que foi explicitado anteriormente, é dizer que os indivíduos escolherão as "cestas de bens" com maior utilidade total, ou que maximizarão a utilidade. Visto isso, caso se tenha que escolher um plano alocativo, dever-se-á avaliar quais as alternativas, dentre todas, será a mais benéfica. Porém, isso nos leva a outro problema: como avaliar qual plano alocativo é o que maximiza a utilidade? Em outras palavras, como avaliar se a combinação de fins que o indivíduo buscará alcançar com seus meios apresenta maior importância que o combinação alternativa?

\section{O segundo problema - o problema do cálculo econômico}

O problema supracitado é conhecido como o problema do cálculo econômico: o problema de avaliar o custo de oportunidade de cada escolha, e por consequência, o custo de oportunidade de um plano alocativo, em outras palavras, avaliar a importância relativa dos usos alternativos de um meio. Tal avaliação depende do conhecimento de três fatores: a ordem das preferencias, maneiras de usar os e quantidade dos meios ${ }^{3}$.

Cada instituição econômica terá sua maneira específica de avaliar os custos de oportunidade, mas, em última instância todos os métodos são meios da possibilidade de avaliar custos e benefícios. Por exemplo, uma economia socialista pode avaliar se um uso é melhor que outro comparando as utilidades marginais de cada uso com auxílio de um supercomputador, de maneira similar uma economia de mercado em que os indivíduos fazem a mesma análise, mas auxiliados pelo sistema de preços. Ambos casos são diferentes maneiras específicas de

\footnotetext{
${ }^{2}$ Esse é o argumento da semelhança formal entre todas as instituições econômicas. Qualquer que seja tal instituição, os agentes terão que efetuar escolhas, residindo, aqui, o problema econômico. Apesar de que não é ilógico que exista uma situação em que não exista tal problema, ela dificilmente corresponde à realidade que a sociedade humana já enfrentou e enfrenta, e possivelmente jamais vai enfrentar.

${ }^{3}$ Devemos notar que dado um conjunto de teorias sobre como usar os recursos e uma serie de preferências, tem-se apenas plano alocativo. Destas duas variáveis apenas uma é puramente exógena para nossa análise, as preferencias, visto que a ciência econômica não tem por objetivo explicar as preferências dos indivíduos. Por sua vez o conhecimento pode ser inicialmente exógeno, mas ele será modificado pelos eventos do sistema econômico, se tornando assim parcialmente endógeno. Também é importante deixar claro que normalmente se fala que os três tipos de variáveis são: preferências, quantidade dos meios/bens e as maneiras de se usar os meios (tecnologia), como foi dito no início da seção. Ao falar que são duas variáveis que determina os planos dos indivíduos, está se dizendo que é o conhecimento da quantidade disponível e das potencialidades produtivas dos meios que fazem parte do processo. O sucesso e fracasso de tais conhecimentos dependem do quão próximo eles correspondem ao verdadeiro "valor" dessas variáveis. Devemos também realçar que apesar de que apenas um plano pode ser inferido dessas variáveis, não implica que existe correspondência de um para um entre esse conjunto e o plano, visto que diferentes conjuntos de preferência e conhecimento podem gerar um mesmo plano alocativo.
} 
efetuar a mesma avaliação. Qualquer instituição econômica que conseguir comparar a utilidade marginal das alternativas será capaz de efetuar o cálculo econômico.

Para ilustrar melhor algumas peculiaridades da elaboração aqui feita, faz-se a seguinte indagação: existe algum modelo socialista que, a princípio, consegue resolver o problema do cálculo econômico? A resposta é sim.

Cumpre esclarecer que os modelos socialistas neoclássicos fornecem uma maneira correta de efetuar o cálculo econômico, visto que, basicamente, aplicam a lógica da escolha aos seus modelos, seja através da réplica do processo de avaliação de uma economia de mercado, ou de uma versão do método usado pelos indivíduos isoladamente. Isso se deve que as equações de seus modelos nada mais são do que formalizações da lógica da escolha, e se o governo socialista tiver sob sua posse os conhecimentos necessários se segue que poderiam efetuar tal cálculo.

Autores da tradição austríaca como Rothbard, Salerno e Hoppe, que buscam mostrar que o socialismo é impossível, porquanto os métodos de efetuar o cálculo econômico dos modelos neoclássicos são a princípio impossíveis, fracassam. Isso não implica em que o socialismo seja possível, apenas por ser a princípio possível. A insistência desses autores de que o socialismo é impossível a princípio, se deve a suas epistemologias e metodologias que tratam a ciência econômica como dedutiva de um axioma justificado como verdadeiro. Devido a tal característica, provar que o socialismo entraria em contradição com tal axioma seria demonstrar definitivamente que o socialismo é impossível. Se o socialismo for coerente com tal axioma, logo a sua impossibilidade, não seria garantida por tal. Dessa forma, a certeza proveniente do esquema acima elaborado não estaria presente (BARBIERI, 2013, p.215-224; 2001, p. 124-128).

A elaboração acima pode parecer estranha para quem está familiarizado com o tratamento de Mises, que assim ensina:

Não precisamos nos deter no exame das condições primitivas da economia doméstica de camponeses autossuficientes, que lidavam apenas com processos de produção extremamente simples. Neste caso, não havia necessidade de cálculo econômico, uma vez que se poderia comparar diretamente o custo e o benefício. Se quisessem camisas, cultivavam o cânhamo, desfiavam, teciam e cosiam. Podiam, sem recorrer a qualquer cálculo, decidir se o trabalho e o esforço despendido seriam compensados pelo produto. Mas para o homem civilizado, o retorno a este tipo de vida não é mais admissível. (MISES, 2010, p. 260)

Aparentemente, existe uma contradição entre o que Mises chama de problema do cálculo econômico e o que aqui se chama, visto que a elaboração aqui, claramente, explicita a comparação dos custos e benefícios de maneira direita, como um camponês. Todavia o problema é apenas terminológico.

O problema do cálculo econômico, como proposto por Mises, é quando se tem que avaliar as alternativas de como alocar recursos para decidir qual é a maximização da utilidade sobre as condições de uma economia complexa, conforme citação acima. o acima exposto. Mas a complexidade em si não seria o suficiente para entender a proposta de Mises. Isso se deve a nossa segunda condição: o desequilíbrio, como o próprio Mises descreve, em seu primeiro trabalho sobre o tema: 
O estado estático pode dispensar o cálculo econômico porque nele os mesmos eventos da vida econômica ocorrem repetidamente; e se pressupormos que o primeiro arranjo de uma economia socialista estática será baseado no estado final em que se encontrava a economia competitiva, podemos até conceber - de um ponto de vista econômico - um sistema de produção socialista racionalmente controlado. Mas isso é possível apenas conceitualmente. Por ora, deixaremos de lado o fato de que um estado estático é algo impossível na vida real, uma vez que os dados econômicos estão em constante mudança. (A natureza estática da atividade econômica é apenas uma suposição teórica que não corresponde a nenhuma situação real, por mais necessária que possa ser para o nosso raciocínio e para o aperfeiçoamento do nosso conhecimento econômico). (MISES, 2010, p. 32-33)

Fica claro que, para Mises (2010), o problema do cálculo econômico compreende todo esse complexo de problemas aqui abordado. Tendo isso em mente, podemos entender as diferenças entre o uso do termo em Mises e no presente artigo.

Para resolver o problema econômico, é necessário resolver o problema do cálculo econômico. A solução do problema do cálculo econômico requer que nosso conhecimento sobre as possibilidades de uso dos bens econômicos, seja dado de tal forma que, ao efetuar o plano alocativo, o indivíduo não encontre nenhum problema. Em outras palavras, que sua expectativa ocorra como esperado, ou pelo menos correto o suficiente para boa parte do seu plano ocorrer satisfatoriamente ${ }^{4}$.

Podemos chamar esse conhecimento alocativo correto, definido como conjunto de teorias ou hipóteses de como utilizar os bens econômicos, de conhecimento perfeito; e quando parcialmente incorreto, de conhecimento alocativo imperfeito. Se a solução do problema do cálculo econômico requer que pelo menos boa parte do conhecimento alocativo seja correto, o que ocorre quando ele está incorreto?

\section{O terceiro problema - o problema do conhecimento}

\section{Examinar-se-á, a partir de agora, o problema do conhecimento.}

Como consoante já se afirmou, para que se efetue corretamente o cálculo econômico devese possuir conhecimento correto. A questão que se apresenta, então, é como obter ou descobrir o conhecimento correto, ou, ainda, como corrigir o conhecimento equivocado?

A resposta para aludida indagação pressupõe, no entanto, certas deliberações, em especial, deve-se ter em mente as diferentes consequências em relação a uma economia em que o conhecimento é correto ou perfeito, e, outra, que o conhecimento é errado ou imperfeito.

Pensa-se, como exemplo, em um indivíduo, ou em um conjunto de indivíduos, que detenha conhecimento correto a respeito de como usar os bens econômicos, ou melhor, a respeito.

\footnotetext{
${ }^{4} \mathrm{~A}$ inclusão dessa possibilidade de os seus planos ocorrerem majoritariamente como o esperado, mas não necessariamente exatamente como planejado, vem da distinção entre um sistema em desequilíbrio, mas organizado, e um em equilíbrio e organizado. Um indivíduo, e principalmente um sistema econômico, devem apresentar um certo grau de organização/coordenação interna e externa do plano alocativo para que tal economia possa permanecer operando e logo significa que resolve suficientemente bem o problema econômico e do cálculo econômico.
} 
No caso de um indivíduo isolado, há necessidade de que este conheça sua preferência e as possibilidades de como usar os recursos disponíveis, resultado de suas ideias da disponibilidade de certos meios e suas possibilidades produtivas. Por sua vez, na hipótese de uma economia que possua vários indivíduos interagindo entre si, o agente necessita ir além no sentido de conhecer como os demais reagirão as suas ofertas e demandas.

Temos então que uma economia de mercado adiciona uma outra dimensão de conhecimento necessário por parte dos agentes, enquanto no socialismo tal dimensão estaria ausente, ou na melhor das hipóteses, possuindo menor relevância.

De qualquer forma, se os indivíduos possuírem conhecimento alocativo correto, eles irão ter planos alocativos internamente coordenados e no caso de vários indivíduos além da coordenação interna de seus plano, terão planos alocativos coordenados entre si.

Se os planos deles estão perfeitamente coordenados, podemos dizer que não existiria mudança econômica, num sentido específico de que toda mudança nessas variáveis (preferencias, técnicas produtivas, disponibilidade de recursos etc.) seria prevista corretamente, e, logo, do ponto de vista do agente, as coisas ocorreram como esperado, logo seus planos não precisam mudar. Por consequência, todos planos se realizariam exatamente como previsto. Isso, por definição, é o equilíbrio geral (EG) (HAYEK, 1948, p. 46). Se conhecimento perfeito é condição necessária e suficiente para o EG, então se há a conhecimento imperfeito, estamos, então, numa situação de desequilíbrio.

Ora, Mises, quando propôs o problema do cálculo econômico (no sentido por ele utilizado) deixou claro que estava falando de uma economia em desequilíbrio, como explicado acima. Para resolvermos, da melhor maneira possível, o problema econômico, o cálculo econômico deve ser efetuado da maneira mais correta possível, porém, para isso, é necessário que o conhecimento dos agentes seja o mais correto possível, e, logo, dada uma situação de desequilíbrio (que é a situação real), é necessário que tenhamos um processo de correção de erros de conhecimento. Em especial devido a que erros passados afetam as condições iniciais presente.

A falta desse processo de correção de erros, ou descoberta de conhecimento correto, leva a um aumento da descoordenação dos planos dos agentes e logo descoordenação interna. Com isso os erros além de não serem corrigidos, vão se "acumulando", ou piorando, devido a fontes endógenas de mudanças nas variáveis econômicas e no desgaste da estrutura produtiva (consumo de capital), que por sua vez leva a uma queda na complexidade econômica, e produtividade.

Imaginemos a situação econômica de Crusoé. Ele tem a escolha entre usar seu trabalho para pescar, caçar, e colher frutas. Se ele superestimar a produtividade física dele na caça, visto que ele era ótimo em caçar animais em sua terra natal, a tendência é ele alocar mais trabalho para a caça. Porém, esse conhecimento dele sobre sua produtividade física em caçar estiver errado, digamos que ele acreditava que tinha tal produtividade pois os animais seriam os mesmos, e logo suas táticas de caça seriam igualmente eficientes. Ele irá fracassar no seu plano alocativo, e irá revisar esse seu conhecimento. Essa elaboração simplista está por trás dos modelos de Socialismo de Mercado em que mecanismos de tentativas e erros são inseridos.

A correção por tentativas e erros aparenta ser a única viável pois é impossível saber ex ante de testar o conhecimento alocativo se ele corresponde ou não com a realidade; e como será defendido mais adiante esse processo é o único teoricamente existente. 
Fica mais fácil visualizar o problema em seu correto escopo quando analisamos uma economia mais complexa. Imagine que temos Crusoé, novamente, porém agora ele achou toda uma cidade cheia de equipamentos. Ele saiu de uma economia com poucos bens de capital, e por consequência com pouca complexidade, para uma economia com muitos bens de capital e com alta complexidade. Com todos esses recursos, ele tem que elaborar teorias de como pode os usar. Após fazer isso e decidir um plano alocativo, ele coloca seu plano a teste, se ele cometeu algum erro, onde está o erro?

Qual dos fatores ele superestimou ou subestimou sua produtividade, será que o timing de cada etapa do plano estava correto? Será que a quantidade real de um fator nas ruinas da cidade era menor do que ele esperava? Será que ele não levou em consideração corretamente as diferenças de qualidades dos bens de capital similares fisicamente? Será que ele erroneamente não considerou um fator de produção escasso como não sendo escasso? Essas perguntas basicamente se repetem para cada passo no processo produtivo que ele der.

Temos uma serie de possibilidades de qual parte do conhecimento dele estava errado e que o fez alocar recursos de maneira ao plano alocativo não ser internamente coordenado, a situação piora se tivermos que ter coordenação entre os indivíduos. Até mesmo no simples caso que postulamos de Crusoé caçando, temos que o erro dele poderia estar que na região que ele caçou erra ruim, o momento que ele caçou, e outros fatores ${ }^{5}$.

Agora imaginemos isso, para uma economia extremamente complexa, como a atual no mundo. O número de possibilidades de qual conhecimento errado está causando meu plano alocativo falhas é enorme. Esse problema não é exclusivo do conhecimento sobre as possibilidades de uso dos recursos, mas sim de todo conhecimento.

Este é o problema chamado de Problema da Subdeterminação Holista. Duhem o apresentou nos seguintes termos:

A única coisa que a experiência nos informa, é que entre todas as proposições que serviram para prever dado fenômeno e para constatar que ele não se produziu, há pelo menos um erro. Mas onde reside esse erro, é o que ela não nos diz. (DUHEM, 1989, p. 93)

Duhem assume que só podemos derivar consequências empíricas de uma hipótese se ela está conjunta a outras hipóteses e crenças. Assim, quando uma predição empírica é falseada e, portanto, há inconsistência entre a conjunção das hipóteses, não se pode saber em qual hipótese da conjunção está o problema. Dito isso, todo falseamento de uma teoria é inconclusivo.

Além de Duhem, outro filósofo a lidar com o problema foi Quine (2011). Pode-se interpretar o ponto de Quine como uma generalização de Duhem. Por isso, muitos chamam o problema da subdeterminação Holista de tese Duhem-Quine.

\footnotetext{
${ }^{5}$ Devemos ressaltar que sempre o erro se manifesta como uma relativa supervalorização de uma maneira de usar o recurso. Porém o que "causa" essa supervalorização é indeterminada. Por exemplo, um indivíduo pode ter prejuízo ao decidir produzir um certo produto pois ou superestimou a demanda pelo produto, ou superestimou a produtividade deles, ou um misto de ambos.
} 
Esse problema é levantado diversas vezes como crítica à teoria falseacionista de Popper. Porém, a chave para nosso próximo e último problema está em compreender a resposta de Popper a tal crítica, resposta essa embasada em sua filosofia do Racionalismo Pancrítico ${ }^{6}$.

Para solucionar o problema, Popper (1997) propõe uma solução institucional. Suponhamos que temos um indivíduo isolado, como Crusoé. Se ele tivesse uma abundância de recursos, em especial, o recurso "tempo", não seria implausível supor que ele testaria uma alternativa de cada vez, ou, pelo menos, um conjunto pequeno simultaneamente, de onde estaria o erro de seu conhecimento. Paralelamente não é impossível imaginar um ditador em uma economia em que as dotações iniciais a cada iteração são as mesmas, poderia, com suficiente tempo, resolver o problema em uma economia de qualquer complexidade.

Todavia, fora desse estado irreal, a nossa capacidade de explorar quais partes de nosso conhecimento estão erradas é extremamente limitada. Como Popper explica, ao tratar desse problema, só que no contexto das tradições, sozinhos não teríamos ido mais longe que Adão (POPPER, 1994, p. 155).

Popper propõe que façamos uso das diversas visões teóricas sobre onde está o erro, além de diversas visões teóricas de como decidir onde está o erro, para criar um processo social de tentativa e erro através de uma rede de testes, críticos e não críticos ${ }^{7}$, que permitam gerar avaliações comparativas entre os graus de corroboração das diversas teorias. Porém, para utilizar essa variedade de conhecimentos, é necessário que as instituições sejam tais que permitam fazer o uso.

Sem a colaboração de vários indivíduos, tanto no passado, quanto no presente, não teríamos como ter explorado tantas vias e deixado nossos resultados comparativos em livros etc., para os que vieram e os que estão por vir. Temos que, em Popper, a solução para o problema da tese Duhem-Quine é o uso de uma diversidade teórica para explorar diversas rotas sobre onde estaria tal erro, ou seja, criar uma exploração simultânea em um espaço teórico, análogo ao espaço genético de Dawkins (2001, p. 107-108). Essa exploração simultânea forma uma rede de testes críticos que fornecem o resultado comparativo das diversas teorias, que nos permite aferir qual possibilidades de erros são mais frutíferas e aparentemente são onde "realmente" está o erro ${ }^{8}$.

Para Popper, o conhecimento é visto como progressivo apenas quando sujeito a um processo de tentativa e erro9. Também se aceita, nesse trabalho, que o problema da tese Duhem-Quine é universal para todo conhecimento e que a solução de Popper é também universal, porém as instituições necessárias para sua aplicação mudam de caso a caso. Assim, como na ciência, a economia lida, também, com conhecimento. Apesar de serem tipos diferentes de conhecimento, visto que a ciência lida com conhecimentos universais, na economia os agentes lidam com conhecimento local, restrito em tempo e espaço. Dessa forma, o "progresso" do conhecimento

\footnotetext{
${ }^{6}$ Sobre a ideia de Racionalismo Pancrítico, ver Bartley (1984) e Popper (1997).

${ }^{7}$ Sobre o conceito de testes críticos e não críticos, ver Popper (2013; 1997).

${ }^{8}$ Apesar disso devido à natureza não justificacionista de tal teoria, sempre é inconclusivo esse processo e openended.

${ }^{9}$ Para uma análise evolucionária do conhecimento, ver Popper (1972) e Campbell (1993).
} 
alocativo é uma maior aproximação com as variáveis base da economia, que por sua vez são tem sua própria dinâmica interna.

Uma diferença relevante é que diferentes interpretações de onde está o erro são frutos de diferentes teorias, a qual chamaremos de conhecimento heurístico, diferem do conhecimento sobre "o mundo", que chamamos de conhecimento objeto, e no caso da economia seu equivalente é o conhecimento sobre as possibilidades de uso dos recursos, a qual chamamos de conhecimento alocativo.

Como visto, o conhecimento alocativo é o conjunto de teorias que um ou mais indivíduos possuem sobre as possibilidades de uso dos bens econômicos, enquanto o conhecimento heurístico é a teoria de como lidar com erros do conhecimento alocativo. São regras de onde atribuir o erro, onde não atribuir, o que conta como uma alternativa viável de mudança no conhecimento alocativo etc. Essa distinção será relevante mais adiante.

A solução do problema do conhecimento é o uso do conhecimento contraditório e conflituoso na sociedade para gerar essa exploração simultânea. A pergunta então é, se um processo descentralizado de exploração é necessário, como colocar em prática essa solução para a tese Duhem-Quine em condições de complexidade e desequilíbrio? Em outras palavras, como fazer uso do conhecimento, tanto heurístico quanto alocativo, disperso, incompleto e contraditório, ou seja, conhecimento errôneo, para criar um processo de descoberta de erros e assim, ao obter conhecimento relativamente mais correto, efetuar o cálculo econômico de maneira mais condizente com as variáveis econômicas subjacentes (preferências etc.)?

\section{O quarto problema - o uso do conhecimento}

O problema do uso do conhecimento foi proposto por Hayek em 1945 (1948, p. 77-91). Seu argumento traz que o conhecimento, seja alocativo, seja heurístico, está disperso na sociedade. Ninguém possui isoladamente conhecimento para solucionar o problema do cálculo econômico, visto que é ignorante, ou seja, tem conhecimento errado ou simplesmente não sabe sobre as diversas variáveis na economia. Devemos então, já que não se tem como saber ex ante quais teorias alocativas são corretas, usar o máximo o conhecimento diverso dos agentes para descobrir os erros, como dito anteriormente.

Porém, Hayek não deixou tão evidente no artigo de 1945 que estava lidando com conhecimento errôneo e incompleto. Em razão disso, diversos autores interpretaram que o argumento de Hayek seria um problema apenas de coleta do conhecimento alocativo disperso na sociedade e do processar centralmente segundo as equações de EG.

Alguns autores classificam o argumento de Hayek como meramente "prático", que, por prático significa "fora da ciência econômica". Essa abordagem é comum entre os autores associados à vertente Rothbardiana, e, curiosamente, por autores neoclássicos, visão claramente refutada ao longo desse artigo, onde em nenhum momento os problemas apresentados não são parte da ciência econômica, apesar de comuns a outros campos. A outra leitura é que a impossibilidade do socialismo funcionar sob condições de economia complexa seria pela natureza tácita e efêmera desse conhecimento $\mathrm{O}$ Governo seria incapaz de centralizar 
conhecimento alocativo pois seria a princípio impossível comunicá-lo e ele seria restrito temporalmente em utilidade.

Ambas interpretações estão erradas, porém, a segunda geralmente não é fruto de má compreensão teórica, visto que a maioria dos autores entende a relevância dos processos de aprendizado e feedback negativo, mas sim fruto da falta de um framework analítico capaz de organizar as relações dos problemas ${ }^{10}$. O que geralmente ocorre é uma confusão entre a natureza tácita do conhecimento heurístico, e a natureza restrita em tempo e espaço do conhecimento alocativo.

O primeiro ponto para se entender é que o conhecimento alocativo nunca é tácito. Todo conhecimento alocativo consiste em saber que, e não saber como, nem saber porque. Não é necessário que eu saiba como eu consigo andar de bicicleta, nem porque consigo, basta que eu saiba que consigo andar de bicicleta a $20 \mathrm{~km} / \mathrm{h}$, a fins de exemplo. Podemos dizer que o conhecimento alocativo sempre é proposicional e logo transmissível.

Se tivéssemos em uma situação de equilíbrio, em que o conhecimento alocativo fosse correto, teríamos que, a princípio, seria possível transmitir e usar tal conhecimento correto. Hayek deixa claro essas características do conhecimento que ele tem em mente:

The peculiar character of the problem of a rational economic order is determined precisely by the fact that the knowledge of the circumstances of which we must make use never exists in concentrated or integrated form but solely as the dispersed bits of incomplete and frequently contradictory knowledge which all the separate individuals possess. (HAYEK, 1948, p. 44-48)

The shipper who earns his living from using otherwise empty or half-filled journeys of trampsteamers, or the estate agent whose whole knowledge is almost exclusively one of temporary opportunities, or the arbitrageur who gains from local differences of commodity prices are all performing eminently useful functions based on special knowledge of circumstances of the fleeting moment not known to others. (HAYEK, 1948, p. 80)

To gain an advantage from better knowledge of facilities of communication or transport is sometimes regarded as almost dishonest, although it is quite as important that society make use of the best opportunities in this respect as in using the latest scientific discoveries. (HAYEK, $\underline{1948}$, p.81)

Hayek, ao utilizar termos como "contraditório" e "incompleto", demonstra que estava tratando de conhecimento errado. Fica mais claro ainda quando fala sobre conhecimento, sobre oportunidades de arbitragem etc., visto que a arbitragem pode, apenas, ocorrer se outros indivíduos estiverem com conhecimento imperfeito, fazendo com que aloquem recursos de maneira a não estarem coordenados em seus planos. Em todo caso, Hayek trata claramente de conhecimento errado, de desequilíbrio, que por sua vez também é disperso.

O segundo ponto é que, tanto para Popper quanto Hayek, existem meios de "comunicação" que transmitem o atual estado da situação problema. Em Popper, livros, vídeos e outros meios

\footnotetext{
${ }^{10}$ Essa interpretação é tão prevalente que mesmo autores que em sua proposta teórica propõe basicamente o mesmo que se propõe aqui, adotam o esquema analítico influenciado por essa interpretação, dificultando assim visualizar a conexão entre os problemas relevantes. Para um caso recente ver Keisling (2015).
} 
de comunicação fazem esse papel, sendo que comunicação aqui apresenta um significado estrito de transmissão de conhecimento ou informação, onde um agente aprende o conteúdo transmitido, enquanto que para Hayek, os preços fazem essa "transmissão" de informações, representando corretamente o atual estado de conhecimento que os agentes possuem, mesmo que esse conhecimento esteja errado ${ }^{11}$. Em outras palavras, os preços não "transmitem" conhecimento alocativo correto ou perfeito, mas representam corretamente o conhecimento alocativo errôneo dos indivíduos, a não observação explicita desse fato leva ao esquecimento de que o principal papel dos preços é a de corrigir teorias alocativas.

Sendo assim, encontrar gaps entre preços de fatores de produção e seus produtos, ou outras coisas do gênero, significa encontrar uma relativa sub valoração de um fator para certo fim $^{12}$. Consequência de um conhecimento alocativo errado. Sem saber, ao tentar corrigir esse gap, na busca pelo lucro, o indivíduo está colocando a prova seu conhecimento frente a vários outros sobre como usar os recursos e por consequência seus preços. O preço então faz com que os indivíduos ajam como se tivessem o conhecimento do outro. É as restrições que os preços impõem no comportamento dos indivíduos, e as oportunidades que geram, que são "informativas" de um ponto de vista externo ao sistema.

Não devemos ler o que foi dito acima como afirmando que os indivíduos inferem dos preços conhecimento, apesar de que podem. Porém, toda e qualquer inferência de conhecimento partindo dos preços será inválida, visto que cada constelação de preços (e quantidades) é compatível com um número enorme de variáveis subjacentes, variáveis essas que incluem o conhecimento dos agentes, de maneira que não se pode inferir partindo dos preços, os conhecimentos dos agentes. Devido a isso, os agentes não têm como inferir perfeitamente dos preços o conhecimento dos outros agentes, e isso sequer é necessário para o funcionamento do mercado. A ideia de que o preço pode ensinar pro agente todo conhecimento que foi usado em sua formação é não apenas errada, mas vai de encontro com a ideia de preços como substitutos de conhecimento.

Feitas essas observações podemos afirmar que o problema do uso do conhecimento é um problema de como fazer com que se utilize a diversidade teórica de interpretações diferentes (ou seja, contraditórias) de onde se errou no uso dos recursos e do porque se errou (de qual hipótese alocativa estava errada) para através do processo de exploração simultânea, gerar testes cruciais, que descobrirá quais interpretações (e seus respectivos planos alocativos associados a eles) estão relativamente corretas, "guiando" recursos e futuras explorações para os "caminhos" corretos. Resolve-se assim o problema do conhecimento, e por consequência, o do cálculo econômico sob condições de desequilíbrio e complexidade.

A solução dada por Hayek é a instituição da propriedade privada, pois ela descentraliza o controle dos recursos permitindo que os indivíduos tenham liberdade de experimentar suas

\footnotetext{
${ }^{11}$ Devemos notar que os preços diferentes de livros etc., não são meios de comunicação no sentido estrito, mas sim operam como se fossem meios de comunicação.

${ }^{12}$ Ao ver um preço "baixo" um indivíduo pode tanto aumentar seu consumo próprio de tal produto, nesse caso ele é um tomador de preços, como pode o achar baixo demais e comprar para revender ou comprar para produzir um produto que tem um preço mais alto que o custo dos insumos e do juros obtendo lucro.
} 
hipóteses e colocar em prática seus planos alocativos derivados deles. Só com propriedade privada podemos fazer o máximo uso do conhecimento alocativo para corrigir os erros alocativos.

Mas esse processo não ocorre apenas no nível do conhecimento alocativo. Ele, também, ocorre no conhecimento heurístico. Para Barbieri (2006, p. 507-534), as empresas podem ser vistas como programas de pesquisa com diferentes regras heurísticas, advindas de diferentes núcleos duros, analogia inspirada por Lakatos (BARBIERI, 2006, p. 518-520). Sendo assim as empresas apresentam diversas interpretações sobre onde os erros passados foram, e logo o sucesso de uma empresa indica o sucesso conjectural de seu conhecimento heurístico, limitando assim no futuro quais tipos de erros e onde estão serão explorados. A qualquer momento, todavia tais teorias heurísticas podem ser continuamente refutadas com o constante prejuízo derivado de más interpretações de onde está o erro no conhecimento alocativo (e o erro no uso dos recursos que deriva disso).

Então, além do conhecimento alocativo ser corrigido e selecionado dentro do mercado, as próprias empresas e seus conhecimentos heurísticos também são. Essa interpretação é completamente válida e coerente com o trabalho de Hayek, visto que o mesmo comenta:

Which goods are scarce, however, or which things are goods, or how scarce or valuable they are, is precisely one of the conditions that competition should discover: in each case it is the preliminary outcomes of the market process that inform individuals where it is worthwhile to search. Utilizing the widely diffused knowledge in a society with an advanced division of labor cannot be based on the condition that individuals know all the concrete uses that can be made of the objects in their environment. Their attention will be directed by the prices the market offers for various goods and services. This means, among other things, that each individual's particular combination of skills and abilities - which in many regards is always unique-will not only (and not even primarily) be skills that the person in question can recite in detail or report to a government agency. Rather, the knowledge of which I am speaking consists to a great extent of the ability to detect certain conditions - an ability that individuals can use effectively only when the market tells them what kinds of goods and services are demanded, and how urgently. (HAYEK, 1978, p. 13)

Hayek (1978) deixa claro que o conhecimento é uma forma de detectar certas condições, ou melhor, certas oportunidades. Então, como reagir a erros prévios, tanto do próprio agente, quanto de outros, se manifesta como oportunidade de alocar os recursos de melhor maneira e é parte essencial do conhecimento heurístico.

Aqui, a relevância do conhecimento tácito é muito maior, visto que boa parte de tal conhecimento heurístico não é sequer compreendido conscientemente pelos indivíduos. Mas ainda assim surge, como visto acima, o problema de corrigir esse conhecimento. Detectar e eliminar as teorias heurísticas erradas, e as substituir por teorias melhores, que aceleram a correção de erros na esfera do conhecimento alocativo.

Mas tudo isso é possível porque a instituição econômica chamada de "livre mercado" permite que indivíduos façam uso de seu conhecimento tanto alocativo quanto heurístico. A pergunta que surge é: algum modelo de socialismo pode fazer o mesmo? A resposta depende de que suas regras institucionais sejam tais que permitam fazer uso do conhecimento disperso para resolver o problema do conhecimento, e, para assim, resolver o problema do cálculo econômico. 
O modelo de Lange, de fato, cria um processo de tentativa e erro parcialmente descentralizado. Porém, como explicita Barbieri (2013, p. 269), o mecanismo de seleção artificial limita as variedades das possibilidades dos erros porque todo erro é apenas um erro de superestimar ou subestimar a demanda.

Já que no modelo de Lange (1937) se pressupõe que as curvas de custo, ou melhor dizendo, as funções produção, são conhecidas, se elimina da modelo a possibilidade de elas estarem erradas. Mas esse pressuposto não é válido, já que não se pode pressupor que conhecemos tais curvas, pois descobrir como elas são de fato é parte do problema a ser resolvido.

Ao pressupor isso os socialistas de Mercado e variantes, limitam as possibilidades de correção de erro em seu modelo. Como fala Barbieri:

É grande a semelhança do argumento de Dawkins com a tese de Mises e Hayek sobre a impossibilidade de cálculo econômico no socialismo sem um sistema de preços de mercado. Preços paramétricos podem dar conta de um aspecto muito limitado da complexa realidade econômica, pois fazem parte de um sistema de seleção artificial. A vantagem do sistema de seleção natural do mercado é justamente lidar com essa complexidade. No mecanismo seletivo dado pelos lucros e perdas, não impomos a priori o que poderia levar a uma vantagem competitiva. No processo evolutivo surgem soluções criativas e inovadoras para gerar tais vantagens. $\mathrm{Na}$ competição econômica, a mesma ideia aparece quando Hayek vê o mercado como um processo de descoberta. (BARBIERI, 2013, p. 169)

Se quisermos, então, inserir no modelo a possibilidade de testar diferentes visões de quais seriam as técnicas produtivas mais econômicas, cada gerente teria que enviar sua proposta para um comitê central, que avaliaria e julgaria sua viabilidade, o que por sua vez, significa que teríamos mais um processo artificial de seleção com base nos critérios do próprio comitê. Alternativamente, o comitê daria total liberdade para os agentes usarem os recursos como planejassem, o que na prática significa ter propriedade privada novamente.

Uma alternativa seria tentar coletar o conhecimento heurístico e usar para simular concorrência empresarial. Todavia a natureza majoritariamente tácita de tal conhecimento impede isso, e mesmo que fosse possível coletar tal conhecimento o problema da correção seria apenas colocado em um nível acima, pois a constante correção descentralizada do conhecimento heurístico também é essencial.

Quanto mais quisermos fazer uso do conhecimento disperso para solucionar o problema do conhecimento, mais caminhamos rumo à propriedade privada. O que significa que uma economia socialista é impossível de funcionar em condições reais, sendo possível apenas em principio e em estados irreais.

\section{Conclusão}

Para resolvermos o problema econômico temos que resolver o problema do cálculo econômico. Se não há possibilidade de conseguir avaliar os custos e benefícios das possibilidades de uso dos recursos, não temos como alocá-los de maneira satisfatória.

A solução do problema do cálculo econômico é a avaliação dos custos de oportunidade de cada escolhas alocativa. Essa solução nos leva a necessidade de que nosso conhecimento 
alocativo esteja majoritariamente correto. Todavia, vimos que esse pressuposto é irreal, posto que, na realidade, nosso conhecimento é falho e cheio de buracos, fato atestado pela incerteza do futuro, a constante revisão de nossos planos, e, devido à própria natureza do conhecimento que nos impede de justificar sua verdade (BARTLEY, 1984).

Sendo nosso conhecimento imperfeito, temos que corrigir seus erros e descobrir que melhores hipóteses consideraremos para trocarmos pelo conhecimento errado. Esse é o problema do conhecimento. Qualquer solução para esse problema deve levar em conta a tese Duhem-Quine, a qual afirma que dado uma conclusão que se mostrou falsa, não temos como saber ex ante qual das premissas é a errada.

A solução do problema do conhecimento é a exploração de diversas alternativas sobre qual hipótese, ou, premissa, equivocada e qual hipótese devemos colocar "em seu lugar". Mas, sobre condições de alta complexidade, recursos limitados e memória do sistema, o processo deve ser feito o mais rápido e com o menor gasto de recursos possível. Para isso, é necessário usar a diversidade de conhecimentos alocativos e heurísticos que esteja disponível na sociedade. Ou seja, devemos resolver o problema do uso do conhecimento.

A solução do problema do uso do conhecimento é um conjunto de regras que permite que esse conhecimento alocativo e heurístico possa ser utilizado para criar um processo impessoal de correção de erros, através de uma rede de "testes cruciais/críticos".

No mercado, esse problema é resolvido através da propriedade privada, onde os diversos indivíduos têm liberdade de testar suas hipóteses alocativas, já que possuem propriedade sobre os fatores de produção. Esse uso e interação entre planos contraditórios, originados de conhecimentos contraditórios, servem como uma rede de testes cruciais/críticos em que os preços, e o lucro e prejuízo derivados deles, servem como se fossem um relatório sobre as diferentes teorias, permitindo assim a descoberta mais rápida e eficiente de qual são as melhores maneiras de se alocar os recursos.

Já no socialismo, mesmo nos modelos mais refinados com uso de tentativas e erros, a sua incapacidade de fazer uso tão completo dessa diversidade teórica faz com que os erros se acumulem, o desgaste na estrutura produtiva cresça e a economia entre em colapso.

Essa conclusão é referente a possibilidade de o socialismo funcionar sob condições de complexidade e desequilíbrio, mas, como vimos, em condições irreais, o socialismo seria logicamente coerente, ou modalmente possível.

O framework da Epistemologia Evolucionária Pancrítica é o elemento unificador de nossa interpretação, e, a compreensão de que os problemas que todo conhecimento possui, também, aplicam-se ao conhecimento relevante em nosso problema que permite fornecer esse esquema analítico.

Uma das consequências dessa investigação é a conexão explícita com a ideia de diversidade como parte essencial de sistemas complexos, como apresentado por Scott E. Page (2011), visto que é a diversidade inerente ao sistema de mercado que permite que ele solucione o problema econômico de maneira satisfatória em um mundo de constante mudança, e logo, de constante adaptação por parte do sistema. Outra conexão é com o conceito de "Fine grain exploration" como apresentada por Melane Mitchell (2009, p. 182). Essas conexões explícitas podem contribuir para a cooperação de pesquisa entre a tradição austríaca e a de complexidade. 
Todavia, o tema, não está e nunca vai estar "finalizado". Nada impede que alguém elabore um modelo que resolva todos esses problemas que, por sua vez, trará uma série de novos debates. Mas, por hora, a conclusão desse artigo se sustenta no sentido de que não há possibilidade alguma do socialismo funcionar sob as condições presentes na realidade. Convido a todos que se interessarem pela abordagem a complementá-la e a criticá-la, para que possamos assim dar mais um pequeno passo rumo a um melhor entendimento do problema. Assim como criticar qualquer exagero por parte desse trabalho sobre suas contribuições.

\section{Referências}

BARBIERI, Fabio. A História do Debate do Cálculo Econômico Socialista. São Paulo: Instituto Ludwig von Mises Brasil, 2013.

BARBIERI, Fabio. O Processo de Mercado na Escola Austríaca. São Paulo: Universidade de São Paulo, 2001.

BARBIERI, Fabio. Filosofia da Ciência Como Ferramenta Microeconômica. Nova Economia, v. 16, n. 3, p. 507-534, 2006.

BARTLEY, William Warren. The Retreat to Commitment. La Salle: Open Court, 1984.

BERTALANFFY, Ludwig von. Teoria Geral dos Sistemas: Fundamentos, Desenvolvimento e Aplicações. Petrópolis: Vozes, 2006.

CAMPBELL, Donald T. The evolutionary Epistemology. In: BARTLEY, I.; RADNITZSKY, W. (eds.). Evolutionary Epistemology, Rationality, and of the Knowlodge. Chicago: Open Court publishing Company, 1993.

DAWKINS, Richard. O relojoeiro cego. São Paulo: Companhia das Letras, 2001.

HAYEK, Friedrich August. Competition as a Discovery Procedure in new Studies. Philosophy, Politics and Economics. Londres: Routledge, 1978.

HAYEK, Friedrich August. Individualism and Economic Order. Chicago: Routledge, 1948.

HORWITZ, Steven. Monetary Calculation and the Unintended Extended Order: The Misesian Microfoundations of the Hayekian Great Society. Review of Austrian Economics, v. 17, n. 4, 2004.

KEISLING, Lynne. The Knowledge Problem. In: BOETTKE, Peter J.; COYNE, Christopher J. (eds). The oxford handbook of austrian economics. New York: Oxford University Press, 2015.

LANGE, Oskar. On the Economic Theory of Socialism: Part One. The Review of Economic Studies, v. 4, 1937.

MILLER, David. Critical Rationalism: A restatement and defence. La Salle: Open Court, 1994.

MISES, Ludwig von. O cálculo econômico sob o socialismo. São Paulo: Instituto Ludwig von Mises Brasil, 2012.

MISES, Ludwig von. Ação Humana: Um tratado em Economia. São Paulo: Instituto Ludwig von Mises Brasil, 2010 .

MITCHELL, Melane. Complexity: a guided tour. New York: Oxford University Press, 2009.

NORTH, Douglass C. Instituições, Mudança Institucional e Desempenho Econômico. São Paulo: Três Estrelas, 2018. 
SAY, Jean-Baptiste. Letters to Mr. Malthus and the Catechism of Political Economy. Alabama: The Ludwig von Mises Institute, 2008.

SMITH, Adam. A riqueza das nações. São Paulo: WMF Martins Fontes, 2016.

PAGE, Scott E. Diversity and Complexity. New Jersey: Princeton University Press, 2011.

POPPER, Karl Raimund. A Lógica da Pesquisa Científica. São Paulo: Cultrix, 2013.

POPPER, Karl Raimund. Objective Knowledge: an evolutionary approach. Oxford: Oxford University Press, 1972.

POPPER, Karl Raimund. Conjecturas e Refutações. Brasília: Editora UnB, 1994.

POPPER, Karl Raimund. O Realismo e o Objectivo da Ciência: pós escrito à lógica da descoberta científica. Lisboa: Publicações Don Quixote, 1997.

ROBBINS, Lionel. Um ensaio sobre a natureza e a importância da Ciência Econômica. São Paulo: Saraiva, 2012.

QUINE, Willard van Orman. Palavra e Objeto. Petrópolis: Vozes, 2010.

QUINE, Willard van Orman. De um ponto de vista lógico. São Paulo: UNESP, 2011.

RECEBIDO EM: 21/04/2019

APROVADO EM: 24/04/2019 